\title{
Filología y humanidades digitales: un repertorio toponímico del Magreb
}

\author{
Philology and digital humanities: \\ a toponymic repertoire from the Maghreb
}

\author{
MIGUEL ÁNGEL MANZANO ${ }^{a}$ \\ DIEGO MELO CARRASCO ${ }^{b}$
}

${ }^{a}$ IEMYRhd-Universidad de Salamanca, España.

Correo electrónico: mmanzano@usal.es

${ }^{b}$ Universidad Adolfo Ibáńez, Chile.

Correo electrónico: diego.melo@uai.cl

\begin{abstract}
El presente artículo tiene por objeto la presentación parcial del proyecto coordinado de investigación, Geografía Cultural del Magreb Islámico y Dinámicas Humanas en el Norte de África (MAGNA), y más concretamente el subproyecto 1 integrado en él, Geografía Cultural del Magreb Islámico Medieval y Moderno en la Red (GEOMAGRED). Concebido como un portal de acceso abierto en Internet, GEOMAGRED ofrecerá un diccionario de topónimos magrebíes extraídos de las fuentes árabes, no árabes y otros repertorios documentales. Organizará la información en diversos campos de interés, de los cuales los dos primeros (la denominación estandarizada del topónimo y su localización) serán obligatorios. En el trabajo se mencionarán algunos antecedentes necesarios para la génesis y desarrollo del proyecto, y asimismo se ofrecerán algunos ejemplos de la presentación de los datos que estarán a disposición de los especialistas e interesados en la historia y la geografía del Magreb.
\end{abstract}

Palabras clave: Magreb, toponimia, geografía araboislámica, geografía cultural, humanidades digitales.

The aim of this article is the partial presentation of the coordinated research project, Cultural Geography of the Islamic Maghreb and Human Dynamics in North Africa (MAGNA), and more specifically the subproject 1 integrated in it, Cultural Geography of the Medieval and Modern Islamic Maghreb on the Web (GEOMAGRED). Intended as an open access portal on the Internet, GEOMAGRED will offer a dictionary of Maghrebi toponyms extracted from Arabic, non-Arabic and other documentary sources. It will organize the information in several fields of interest, of which the first two will always be required: the standardised name of the toponym and its location. The paper will mention some background information about the genesis and development of the project 
and will also provide some examples of the data presentation that will be available to specialists and people interested in the history and geography of the Maghreb.

Key words: Maghreb, toponymy, Arab-Islamic geography, cultural geography, digital humanities.

\section{INTRODUCCIÓN, TRADICIÓN Y MODERNIDAD: LA GÉNESIS DE UN PROYECTO SOBRE EL MAGREB}

Actualmente el acceso a la información a través de la Red se ha convertido en una cuestión fundamental para cualquier tipo de actividad, y más aún en el caso de la investigación científica. Repositorios, bases de datos, accesos a archivos, imágenes, trabajo en conjunto coordinado, etc., son elementos que cualquier investigador, independientemente del campo y área de estudio, necesita para desarrollar su trabajo. A lo anterior ha de añadirse el papel predominante que han adquirido, en los últimos dos lustros, las Humanidades Digitales, concepto que se constituye como un campo diverso y aún emergente que no es fácil de definir. Más bien parece tratarse de una expresión estratégica (Kirschenbaum 2012), un marco amplio que abarca tanto el uso de las tecnologías de la información en la investigación en humanidades y ciencias sociales, como la reflexión teórica en torno a las relaciones entre estas disciplinas y las nuevas tecnologías, el cambio cultural y social por la fuerte influencia de internet o las manifestaciones culturales en formato digital (RodríguezYunta 2014: 453).

Sin ánimo de profundizar en los orígenes y posterior desarrollo de este concepto, sí puede señalarse el hito principal para contextualizarlo. Según Rojas Castro (2013: 75), el nacimiento de las Humanidades Digitales se remontaría a 1949 de la mano del jesuita Roberto Busa (1913-2011). Para desarrollar su Index Thomisticus, una concordancia en latín de las obras de santo Tomás de Aquino y otros autores, este sacerdote consultó al fundador de IBM, Thomas J. Watson, y empleó tarjetas perforadas que leía un ordenador para clasificar alfabéticamente las entradas de un índice de más de once millones de palabras. El proyecto tardó veinticinco ańos en ofrecer los primeros resultados, que empezaron a publicarse a partir de 1974. Los volúmenes impresos alcanzaron la cifra de cincuenta y seis, que en 1992 dieron paso a una versión en CDROM y luego otra en DVD. Finalmente, en 2005, el Index Thomisticus fue publicado en Internet y todavía a fecha de hoy puede accederse a él. Todo ello hizo que, a la muerte de Busa, se lo reconociera como fundador de la disciplina, acaso por ser el primer investigador que protagonizara directamente ese tránsito "de la informática humanística a las humanidades digitales" (Spence 2014: 39-40).

Mucho tiempo ha transcurrido desde aquella época, si bien la amplitud de miras de proyectos como el de Busa acaso sean la mejor explicación del auge que han alcanzado las Humanidades Digitales en nuestros días. Hace unos pocos años, pensar en la elaboración de un gran diccionario de topónimos magrebíes, basado en la información proporcionada por la fuentes árabes (no solo las de carácter geográfico o cronístico, sino en otras de importante valor histórico), en relatos documentales escritos en otras lenguas, y en otras monografías 
específicas, hubiera sido un trabajo monumental no exento de múltiples riesgos: pérdidas de información, omisiones, repeticiones; en fin, un sinnúmero de erratas, producto de la ingente cantidad de información para procesar, expuesta al constante fallo humano.

Sin embargo, esta es la propuesta que aborda el siguiente trabajo: la presentación parcial del proyecto coordinado de investigación, avalado por el Ministerio de Ciencia, Innovación y Universidades de España en 2017 y todavía en fase de desarrollo, que lleva por título Geografía Cultural del Magreb Islámico y Dinámicas Humanas en el Norte de África (MAGNA). Dicho proyecto está integrado a su vez por dos subproyectos: Geografía Cultural del Magreb Islámico Medieval y Moderno en la Red (GEOMAGRED), dirigido por Miguel Á. Manzano y Dinámicas Humanas en el Norte de África: Poblamiento y Paisaje en Perspectiva Histórica (DHUNA), dirigido por Helena de Felipe (Universidad de Alcalá).

El propósito fundamental de esta investigación coordinada se resume brevemente en pocas líneas: la creación de un portal de contenidos geográficos sobre el Magreb en Internet, en el cual la información se estructure en torno a los topónimos y los grupos humanos. La cronología abarcaría desde el período preislámico (para el subproyecto DHUNA) y llegaría hasta la edad moderna (para ambos subproyectos), habida cuenta de que más allá de este período se consolida un proceso de cambio en la historia norteafricana que resta protagonismo a la tradición cultural arabo-bereber característica de este territorio (presencia de potencias europeas, expansión del imperio otomano, etc.).

Este reto científico del proyecto MAGNA — posiblemente impensable fuera de las Humanidades Digitales, como ya se ha dicho- recoge el inmenso legado de los geógrafos y cronistas musulmanes, para someterlo a la sistematización, la comparación y el análisis propio de la investigación histórica, y ofrecerlo no solo a los especialistas, sino también a un público más amplio que pudiera interesarse por el tema. En última instancia la investigación planteada asume dos hipótesis complementarias: de un lado, se aúna la tradición existente entre los estudios filológicos, la toponimia y el poblamiento humano; de otro, se emplea Internet como herramienta universal de difusión de resultados, sin que por ello haya que renunciar a una metodología científica que es característica de las Humanidades y que, por lo tanto, también debería de serlo de las Humanidades Digitales.

En otro orden de cosas, conviene asimismo señalar que MAGNA es un proyecto en el que convergen múltiples enfoques y planteamientos teóricos, como no podría ser de otro modo al abordar la geografía y la historia del Magreb con una mínima amplitud de miras. Sin tener en cuenta nuevas ediciones y traducciones de fuentes, estudios de interdisciplinariedad textuales, trabajos de geografía y toponimia, monografías sobre lengua y poblamiento bereber, la existencia de portales de contenidos digitalizados específicos, o nuevas herramientas tecnológicas para los estudios árabes e islámicos — por citar tan solo algunas referencias indispensables-, no tendría sentido embarcarse en un proyecto de tales proporciones.

Sería muy prolijo hacer un repaso exhaustivo de todas ellas, si bien puntualmente cabe resaltar las más destacadas. Desde luego, para todos los interesados en la geografía araboislámica resultó fundamental la publicación, ya iniciada en el último tercio del siglo XIX de la Bibliotheca Geographorum Arabicorum por de Goeje que abrió paso a numerosos 
estudios posteriores entre los que ha de tener una mención especial la monumental obra de Miquel (1973-1988). Fue este autor quien puso de relieve la valiosa aportación de la tradición araboislámica a la geografía humana y cultural, lo cual favoreció la aparición de estudios posteriores. Entre ellos, destacan los dedicados al género de al-masālik wa-l-mamālik (como el clásico de Roldán y Valencia 1988), que todavía hoy sigue siendo objeto de análisis (Franco Sánchez, 2017 y 2018). Pero también resultarán de gran interés los trabajos sobre cuestiones fundamentales para la propia disciplina (por ejemplo, el trabajo de Brauer, 1995, centrado en el análisis de las nociones de límites y fronteras en la geografía araboislámica) y, entre ellos, la cartografía (véase, por ejemplo, Tibbets 1992, Franco Sánchez 2005 y 2008, y más recientemente Pinto 2016 o Kahlaoui 2017), los estudios de conjunto (como el reciente de Tixier du Mesnil 2014), o las revisiones críticas absolutamente necesarias sobre la bibliografía y las fuentes (Franco Sánchez 2019a y 2019b).

Centrándonos en estas últimas, habrá de insistirse en la importancia de las reediciones o nuevas traducciones. Ellas han promovido nuevas contribuciones y han supuesto una aportación fundamental al conocimiento geográfico. Así, es necesario destacar la clásica revisión de al-Idrīsī, hecha por Bresc y Nef (1999), o la muy reciente traducción inglesa del Kitāb al-buldān de al-Ya' qūbī, realizada por Gordon, Robinson, Rowson y Fishbein (2018). Además, como muy pronto se manifestó el interés que los geógrafos musulmanes mostraron por el Occidente islámico y el Magreb, también aparecieron extractos, traducciones parciales o contribuciones que hicieron de este territorio un objeto de estudio propio (por citar algunos autores: Marçais 1941; Hadj-Sadok 1949; Pellat 1950; y más recientemente Manzano 2017).

No menos prolífico ha resultado el interés por la toponimia, materia clásica en el campo de la filología y los estudios árabes (bastará recordar el clásico trabajo de Terés, 1986). Para la concepción de MAGNA podrían señalarse numerosísimos trabajos sobre aspectos y particularidades de los enclaves andalusíes y su poblamiento, pero bastará indicar algunas referencias que insisten en la estrecha relación entre al-Andalus y el Magreb en lo referente a este aspecto (por ejemplo: de Felipe 1993 y 1997; Chavarria Vargas 2007; Martos Martín, Martínez Enamorado y Navarro García 2012 o Martínez Enamorado 2013). Estas referencias habrán de unirse a otras más específicamente dedicadas a la toponimia magrebí, cuya tradición historiográfica no es, desde luego, nueva (véase, por ejemplo, Laoust 1942). En particular, es más que destacable la contribución de Ḥasan (2003) a la geografía histórica, pero igualmente relevantes son otras aportaciones locales, como las de Atoui (1996) y Benramdane (1999, 2004 y 2012), y el trabajo conjunto de ambos (2005). Más recientemente conviene mencionar las precisiones sobre emplazamientos problemáticos, como las llevadas a cabo por Van Stäevel y Fili (2006), o los estudios arqueológicos sobre enclaves magrebíes, como, por ejemplo, Akdim, Lazarev y Martínez Enamorado (2014); Callegarin, Kbiri Alaoui, Ichkhakh y Roux (2016), o Aillet, Cressier y Gilotte (2017), entre otras muchas publicaciones que podrían citarse.

Si la toponimia se ha revelado como un espacio de trabajo fecundo, en MAGNA se ha tenido en cuenta asimismo otra línea de investigación antropológica no menos relevante, 
relacionada con el poblamiento tribal y el entorno físico. Es verdad que, aunque más centrada en el presente magrebí, puede ayudar a comprender la perspectiva histórica y, por lo tanto, un pasado no necesariamente muy distante. A este respecto, son muy ilustrativos los estudios de Vignet-Zunz (2017), Moussaoui (2017) o Leveau (2018), si bien hay títulos previos que apuntan en la misma dirección (por ejemplo, Puig 2003 o Mahdi 2007). Desde una perspectiva sociolingüística de referentes bereberes, hay que subrayar la labor desarrollada por el Institut Royal de la Culture Amazighe (IRCAM), cuyas publicaciones también han de ser consideradas. Bastará recordar, por ejemplo, la excelente obra colectiva sobre la huella de la geografía física en la toponimia amazige que coordinó Ramou (2011). Se trata de otro itinerario científico transitado asimismo por Meouak (2015), quien ha utilizado la toponimia reflejada en las fuentes árabes para el estudio de la lengua bereber, obteniendo resultados fundamentales para la geografía cultural magrebí.

Como ya se ha comentado, las referencias bibliográficas que acabamos de mencionar son solo una mínima parte de todas las que podrían ańadirse, habida cuenta de la larga tradición historiográfica existente sobre el norte de África. Pero en la concepción de MAGNA, las nuevas tendencias y herramientas digitales que hacen uso de Internet también han tenido un peso específico. Obras de referencia esenciales, como la última edición de The Encyclopaedia of Islam, THREE, o la Encyclopédie Berbère, pueden consultarse desde hace ya mucho tiempo a través de la red. De igual modo, todos manejamos asiduamente portales como al-Warrāq o al-Maktaba al-Shamela, los cuales contienen innumerables fuentes y textos árabes que pueden consultarse online y resultan útiles, aunque la fiabilidad de sus ediciones presente no pocos claroscuros. A ellas habrán de añadirse otras herramientas todavía en fase de desarrollo, o que se actualizan con frecuencia. Es el caso de Cronoislam, portal para la conversión de fechas islamocristianas o Ibn Jaldún, módulo de teclado que se instala bajo Keyman Desktop y permite realizar la transcripción del árabe en caracteres latinos, además de otros signos no accesibles desde los teclados habituales. Precisamente la organización que distribuye este programa gratuitamente, Sil International, ofrece valiosísimos recursos y tipografías sin coste alguno desde su página web, todo para favorecer el desarrollo de la lingüística mediante herramientas digitales o computacionales.

Con todos estos antecedentes - habremos de insistir en que podrían señalarse muchos más-, es perfectamente comprensible que hayan proliferado los proyectos de investigación relacionados con los Estudios Árabes e Islámicos y las Humanidades Digitales en España. Todos ellos, de temática tan variada como las redes del saber entre los ulemas andalusíes, los aspectos culturales y político-religiosos del Occidente islámico, los intercambios artísticos en el mundo mediterráneo mediante el empleo de sistemas de información geográfica (SIG), o la elaboración de un corpus dialectal de variedades magrebíes y las principales referencias bibliográficas sobre las mismas, han hecho uso de la red o de nuevas tecnologías. Y los resultados que han obtenido o están alcanzando son más que satisfactorios e impensables hace poco más de una década. Desde luego, eran inimaginables cuando hace más de dos surgió el primer portal sobre la lengua árabe y el arabismo que fundaron Xavier Casassas, Jesús Zanón y Miguel A. Manzano (http://arabismo.com) . 


\section{El SubProyecto Geomagred}

Apuntábamos al principio de estas páginas nuestra intención de presentar parcialmente el proyecto coordinado MAGNA, de cuya génesis y concepción hemos hablado en las páginas precedentes. Es parcial, porque solo abordaremos el subproyecto GEOMAGRED en el cual se integran los autores de este trabajo.

Como ya se ha dicho, GeOMAGRed tiene como objetivo básico la creación de un gran diccionario de topónimos magrebíes que se presentarán en un portal web abierto. Este se construirá mediante un sistema de bases de datos y gestión de contenidos de acuerdo con criterios actuales. La presentación de los datos, y su configuración de relaciones y búsquedas — apoyadas en Algolia Search Engine ${ }^{1}$, como motor específico para bases de datos no relacionales - serán los ejes fundamentales del proyecto que, por evidentes razones, ha de inscribirse en el ámbito de las Humanidades Digitales.

El núcleo fundamental para obtener la información estará constituido por las fuentes árabes geográficas y narrativas (aunque no habrán de despreciarse otras obras de valor histórico, como las hagiografías, fuentes jurídicas, etc.), y asimismo otras fuentes y relatos documentales escritos en otras lenguas. A ellos habrán de sumarse los datos obtenidos de los estudios modernos cuya aportación resultará imprescindible, según se ha señalado anteriormente. Por otra parte, conviene tener presente que, al igual que otros proyectos previos de concepción más modesta ${ }^{2}$, GEOMAGRED no se ha concebido originariamente para documentar los topónimos más conocidos y cargados de historia. Rabat, Fez, Marrakech, Tremecén, o Túnez, por poner ejemplos claros, tienen una localización geográfica sobradamente conocida y, en cierto sentido, su historia también resultará accesible. Ahora bien, por nuestra trayectoria como investigadores del Occidente Islámico medieval, hemos podido comprobar en primera persona no pocas veces las dificultades que entrañaba ubicar ciertos enclaves, incluso aun estando cerca de grandes ciudades; máxime si habían desaparecido con el paso del tiempo. Por ello y por la amplitud de sus objetivos, GEOMAGRED, que necesitará de varias ediciones, empezará por topónimos algo menos conocidos para incorporar posteriormente lugares más renombrados. Conviene advertir, con todo, que las fases del proyecto se ceñirán a la propia dinámica derivada de la consulta de las fuentes árabes. A priori parecería razonable establecer la tradicional división del Magreb en tres zonas aproximadamente equiparables a los actuales territorios de Marruecos, Argelia y Túnez y que esta partición coincidiera con etapas del cronograma por desarrollar. Sin embargo, tal procedimiento restaría protagonismo a la historiografía araboislámica, cuya tipología, cronología y características son relevantes per se para el propio proyecto. Habrá que recordar que dicha historiografía aborda el Magreb en su totalidad, con independencia de la mencionada segmentación territorial. Entre otras razones, porque el número de topónimos que registra — aun siendo considerable, como lo es la información

\footnotetext{
${ }^{1}$ https://www.algolia.com

${ }^{2}$ https://dictomagred.usal.es
} 
asociada a ellos- es finito. Un ejemplo que puede resultar orientativo es el $M u$ ' $y$ am albuldān (Diccionario de los países 2012) de Yāqūt al-Hamawī (m. 626 H. / 1229 E.C.) que, manteniendo su concepción enciclopédica (anota un total de 12.953 para todo el territorio del islam), recoge una cifra inferior a trescientos topónimos para el norte de África. Se trata, por tanto, de un valor muy alejado del recuento actual que, según algunos especialistas, alcanzaría los seiscientos mil identificados.

Si nos adentramos en la estructura en que GEOMAGRED presentará los datos, hay que decir que el diccionario toponímico presentará los siguientes campos. A excepción de los dos primeros, que dan sentido a una obra de estas características y son obligatorios, los demás no siempre aparecerán entre los datos que se presentarán en el portal. Dependerá de la información ofrecida por las fuentes:

1. Denominación del topónimo. Aparecerá su nombre en árabe, la transcripción en caracteres latinos, y la actual designación en francés o español, siempre y cuando se den todas las posibilidades. También se recogerán las principales variaciones en la denominación del nombre de lugar, tanto en época medieval como moderna.

Esto aparte, se registrarán asimismo algunas peculiaridades lingüísticas de los enclaves. Al tratarse del Magreb, serán muy abundantes los topónimos de origen amazig o de etimología híbrida, y de ello dan cuenta algunos trabajos publicados por el IRCAM, como ya se ha mencionado.

2. Localización del topónimo. Se ofrecerán los datos extraídos de las fuentes, registrando unidades de longitud originales, y señalando, como ellas mismas suelen hacer, los puntos o enclaves más próximos tomados como referencias. Como es sabido, los autores musulmanes suelen expresar la distancia entre los diversos lugares de una ruta en jornadas, días, millas, parasangas, etc. Por regla general, todas estas unidades de medida tienen sus equivalencias — véase la tabla que sigue a continuación, propuesta por Cardarelli (2003: 76, tabla 3-74), que reproducimos de forma simplificada y con alguna variación:

\begin{tabular}{|c|c|c|c|c|c|c|}
\hline Marhala & Barid & Parasanga & Milla & Pies & Metros & Kms. \\
\hline 1 & 2 & 8 & 24 & 144.000 & 46.080 & 46,08 \\
\hline & 1 & 4 & 12 & 72.000 & 23.040 & 23,04 \\
\hline & & 1 & 3 & 18.000 & 5.760 & 5,76 \\
\hline & & & 1 & 6.000 & 1.920 & 1,92 \\
\hline
\end{tabular}


Sin embargo, a nuestro parecer, es más oportuno respetar la notación original de las distancias, no solo por la fidelidad a los textos, sino por el propio interés que tiene este sistema de medición espacial. Como también lo tienen otras referencias relativas, cuando no aportan medidas concretas. Nos referiremos a la proximidad de otros enclaves, a su inclusión en rutas específicas, a la cercanía con territorios poblados por determinados grupos, etc. Todo ello les sirve a los geógrafos o historiadores para localizar los enclaves. Con todo, en topónimos que han sobrevivido al paso del tiempo, se podría ofrecer la distancia en kilómetros o recurrir a geolocalizaciones mediante el sistema SIG (Sistema de Información Geográfica). De igual modo, en ampliaciones futuras del proyecto, podrían presentarse infografías diversas o mapas por aproximación que ayuden contextualizar el contexto geográfico.

1. Mención de datos históricos relacionados con la economía. Este apartado, de especial relevancia para GEOMAGRED, registrará los sistemas de abastecimiento de agua, regadíos, pozos, etc. Asimismo, guardará información relacionada con los distintos cultivos, árboles frutales, productos elaborados y la situación de los enclaves en relación con las rutas comerciales norteafricanas. Todo ello se hará manteniendo la terminología árabe y su correspondiente traducción.

2. Indicación de fortificaciones, construcciones o ruinas. Este campo registrará información topográfica sobre el urbanismo de los enclaves cuando sea posible (puertas, mezquitas, baños, zocos, construcciones, etc.). También se mencionará la existencia de ruinas.

3. Mención de los grupos humanos relacionados con el topónimo. Algunos topónimos guardan especial relación con grupos humanos o forman parte del dominio de estos. Esta información se incluirá en la base de datos, si bien, se remitirá al subproyecto DHUNA que tiene entre sus objetivos abordar esta información.

4. Relación de personajes históricos y hombres de religión vinculados a la historia del topónimo. Con relativa frecuencia, las fuentes árabes ofrecen datos relativos a protagonistas relevantes para la historia de los lugares magrebíes (emires y sultanes, líderes tribales, rebeldes contra la autoridad política, etc.); protagonistas que serán mencionados oportunamente. Además, teniendo en cuenta la importancia que en el islam magrebí tuvieron los dos modelos socioculturales básicos encarnados en las figuras de santos y ulemas - modelo recurrente al que los gobernantes quisieron emular (véase, por ejemplo, Manzano Rodríguez 2016), la base de datos también recogerá estas figuras cuando su vinculación con los topónimos sea manifiesta.

5. Recopilación de las principales leyendas, tradiciones populares o símbolos que las fuentes atribuyen al topónimo estudiado. Este tipo de relatos abundan en las obras geográficas, aunque no son las únicas. Se reunirán algunos textos significativos que podrían servir para trabajos posteriores (un rastreo de sus orígenes, cotejo de las versiones ofrecidas por las fuentes, etc.). 
6. Inclusión de textos de interés relacionados con el topónimo abordado, en los que se destaque alguna particularidad de carácter histórico o cultural. Se registrarán dos o tres textos que aparecerán traducidos del árabe.

7. Referencias bibliográficas empleadas. Se incluirán las consultadas para cada topónimo dentro de su propio espacio, donde irán abreviadas, pero también en un apartado conjunto, en el que aparecerán completas. De este modo, podrán verse todas las ediciones y traducciones de fuentes, relatos documentales, estudios, etc., que se han empleado para obtener la información recopilada de cada topónimo.

Es importante tener presente que ambos proyectos incluidos en MAGNA comparten las mismas fuentes árabes, cuando menos en esta primera fase de desarrollo. Como ya se ha dicho, estas serán predominantemente de carácter geográfico y narrativo. Pero también se ha aludido a que en ningún caso habrán de soslayarse obras de carácter hagiográfico, jurídico o literario, las cuales, por ser conocidas, omitimos en aras de la brevedad. De igual modo, GEOMAGRED contemplará asimismo las fuentes y relatos documentales no escritos en árabe que puedan completar la información de los topónimos recogidos. En su mayoría son textos conocidos, como el de Juan León Africano o Luis de Mármol Carvajal, pero hay asimismo otras obras coetáneas o anteriores que podrían resultar asimismo relevantes y no se han manejado con tanta frecuencia (verbigracia, Francisco de la Cueva, Aqui comienza la relación de la guerra del reino de Tremecén; Bernardo Rodríguez, Anais de Arzila, etc.; también fuentes medievales, véase, por ejemplo, Manzano Rodríguez, 2019). Además, cabe añadir que GEOMAGRED tendrá asimismo en cuenta textos y documentos procedentes de la misión francesa en el norte de África cuando la información que aporten permita corroborar o completar datos de los textos medievales. Para no alargar en exceso estas páginas, renunciamos a enumerar no pocos títulos interesantes, hoy en día afortunadamente accesibles a través de portales de Internet (como Gallica ${ }^{3}$ o la Bibliothèque Numérique Marocaine $e^{4}$, entre otros). Para tener una muestra de lo que queremos decir, bastará evocar la obra de Gsell (1911). Finalmente se incluirán también referencias bibliográficas modernas que tengan valor o interés para determinados topónimos.

Como muestra de lo que podría recogerse, valgan los siguientes ejemplos:

\section{Ashir / Ašir / ريشأ}

"Ciudad en una montańa de los bereberes del Magreb en el extremo Ifrīqiya occidental en dirección opuesta a Biŷâya (Bugía)". "Se llega a ella desde al-Masilla"

\footnotetext{
${ }^{3}$ https://gallica.bnf.fr.

${ }^{4}$ http://bnm.bnrm.ma:86.
} 
Se localiza a $170 \mathrm{kms}$. Al sur suroeste de Argel, en las montańas Tìṭarī

Recursos hídricos: la fuente ('ayn) de Sulayman la fuente ('ayn) de Talāntīìg ("fuente de calor", en amazige)

Fortificaciones: fortaleza (hișn) muralla $(s \bar{u} r)$

Personajes históricos: Zīrī b. Manād al-Ṣinhāŷī (la construyó en 324 H. /935-936 E.C.)

Buluggīn Yūsuf b. Zīrī b. Manād (361-373 H. / 972-984

E.C.; construyó su muralla)

Referencias: $\quad$ al-Bakrī, Kitāb al-masālik wa-l-mamālik, 724-725.

Yāqūt, Mu'ŷam al-buldān, I, 241.

G. Marçais, "Ashīr", $E I^{2}$, 699a.

\section{Barqa / Barqa / Bقب}

Ciudad situada en la parte oriental del Mágreb, limítrofe con Egipto. Se halla en el interior, a unas seis millas de la Costa del Mar Salado (al-bahr al-mälih), sobre una superficie de tierra fértil de color rojo (turba). Se corresponde con la actual al-Marj, en Libia.

Recursos hídricos: albercas grandes (birak 'izām)

Cultivos: $\quad$ trigo $(q a m h)$

Fortificaciones: $\quad$ muralla $(s \bar{u} r)$ foso $(j a n d a q)$

Topografía: $\quad$ puertas de hierro (abwäb hadìd) arrabales (arbäd)

Personajes históricos: al-Mutawakkil 'alà Allāh (232-247 H. / 847-861 E.C.; construyó las murallas)

Referencias: $\quad$ al-Ya' qūbī, Kitäb al-buldān, 131-132. The Works of Ibn Wädih al-Ya' qübì (The Geography. Kitāb al-buldān), I, 179.

مü مuل لون / Lamta / Nūl Lamṭa 
Ciudad situada a 13 jornadas de Siŷilmāsa y a tres del río Nūn (o Nūl originariamente), primera localidad habitada a la que se llegaba al adentrarse en el Sahara. Hoy en día coincidiría aproximadamente con la localización de Asrīr, a unos 200 kms. de Agadir.
Recursos económicos: vacas (al-baqar)
ganado menor (al-ganam)
adargas (al-daraq)
vestidos (al-safsäriyya y al-burnus)
sillas de montar (surūy), bridas (lûyum) y bastos (aqtäb)
para los camellos

Grupos humanos: Lamṭa, Lamțūna y Ŷazūla (se remitirá al subproyecto DHUNA)

Textos de interés :

[...] On y fabrique les «boucliers Lamța», qui sont les plus admirables qui soient, es plus solides et les mieux élabores. Les peuples du Mghreb les utilisent dans leurs combats en raison de la protection qu'ils procurent et de leur légèreté [...] (al-Idrīisì)

Referencias:

al-Bakrī, Kitāb al-masālik wa-l-mamälik, 853-854.

al-Idrīsì. Nuzhat al-mustāq fì ijtirāq al-äfāq, 224-225.

Idrîsî. Le prèmier geographe de l'Occident, 132-133.

Ma. C. González, Y. Cáceres y J. de Ares, "En busca de Nūl Lamța. La aportación del estudio de la cerámica de Asrir (Guelmin, Marruecos)», en P. Cressier \& E. Frentress (eds.), La Céramique Maghrébine du haut Moyen Âge (VIIIe- X e siècle): État des Recherches, Problèmes et Perspectives. Roma: École française de Roma 2011: 115-131.

Terminaremos esta concisa presentación señalando la dirección en la que se albergará el portal de contenidos de ambos proyectos (https://proyectomagna.org). Este se haya todavía en fase de desarrollo muy incipiente, si bien la intención es ofrecer resultados cuanto antes a todos los interesados en la materia. De hecho, al abrigo del proyecto MAGNA hay ya varias tesis doctorales en curso que mejorarán sin duda el conocimiento del Magreb y renovarán el interés que cada vez más investigadores tenemos hacia la geografía e historia de este territorio. 


\section{OBRAS CITADAS}

Aillet, C., Cressier, P. y Gilotte, S., Sedrata. 2017. Histoire et archéologie d'une carrefour du Sahara médiéval, Madrid, Casa de Velázquez.

Akdim, B., Lazarev, G. y Martínez Enamorado, V. 2014. Le pays des Saddina, Ser. Villes et sites archéologiques du Maroc, vol. IV, Institut National des Sciences de l'archéologie et du Patrimoine, Rabat.

Atoui, B. 1996. Toponymie et espace en Algerie, Aix-en-Provence, Université de Provence - Aix - Marseille I (Tesis Doctoral).

Atoui, B. y Benramdane, F. 2005. "Mondialisation et normalisation des topo $\neg$ nymes et des écritures: le cas de l'Algérie” en Brahim Atoui y Farid Benramdane eds., Nomination et déno $\neg$ mination. Des noms de lieux, de tribus et de personnes en Algérie, Oran, CRASC: 181-197.

Benramdane, F. 1999. "Espace, signe et identité au Maghreb. Du nom au symbole”, Insaniyat, $9: 1-4$.

. 2004. "Toponymie, contact des langues et établissements humains dans la région de Tiaret : une approche diachronique" en Jocelyne Dakhlia (dir.), Trames de langues. Usages et métissages linguistiques dans l'histoire du Maghreb, Institut de recherche sur le Maghreb contemporain, 369-385.

. 2012. "Algérianité et onomastique. Penser le changement : une question de noms propres ?" Insaniyat, 57-58: 369-385.

Al-Bakrī, Kitāb al-masālik wa-l-mamālik. 1992. A. P. Van Leeuwen y A. Ferré (eds.), Túnez: al-Dār al-'Arabiyya li-l-Kitāb.

Brauer, R. W. 1995. Boundaries and Frontiers in Medieval Muslim Geography. Philadephia, The American Philosophical Society.

Bresc, H. y NEF, A. 1999. Idrîsî. Le prèmier geographe de l'Occident, trad. chevalier Jaubert, Paris, GF Flammarion.

Callegarin, L., Kbiri Alaoui, M., Ichkhakh, A, y Roux, J.C. (eds.). 2016. Rirha: Site antique et Médieval du Maroc. I. Cadre historique et géographique général, Madrid, Casa de Velázquez.

Cardarelli, F. 2003. Encyclopaedia of Scientific Units, Weights and Measures. Their SI Equivalences and Origins, Londres, Springer,

Chavarria Vargas, J. A. 2007. “Onomástica árabo-beréber en la toponimia de Castilla-La Mancha: Guadalajara”, Anaquel de Estudios Árabes, 18: 93-116.

Felipe, H. de. 1993. "Berbers in the Maghreb and al-Andalus: settlements and toponymy", The Maghreb Review, 18: 57-62. . 1997. Identidad y onomástica de los beréberes de al-Andalus, Madrid, CSIC.

Franco Sánchez, F. 2005. "El occidente musulmán en los mapas del Mediterráneo de la «escuela de al-Baljî»”, en A.I. Planet y F. Ramos (ed.) Relaciones hispano-marroquíes: una vecindad en construcción, Madrid, Ediciones del Oriente y del Mediterráneo, 35-62. 
. 2008. "Geografía y cartografía en la obra de Ibn Jaldūn”, en J.L. Garrot y J. Martos, Miradas españolas sobre Ibn Jaldún, Madrid, Ibersaf, 195-218.

. 2017. "Al-Masālik wa-l-mamālik: precisiones acerca del título de estas obras de la literatura geográfica árabe medieval y conclusiones acerca de su origen y estructura", Philologia Hispalensis, 31/2: 37-66.

. 2018. "Al-masālik wa-l-mamālik (II). Construyendo una nueva imagen del mundo: ruteros, geografía y cartografía al servicio de la causa ší 'c”, Cuadernos del CEMyR, 26: $111-170$.

. 2019a. "Anotaciones bibliográficas sobre geografía y cartografía de época medieval (I)” al-Qanțara, 40.1: 237-251.

. 2019b. "Anotaciones bibliográficas sobre geografía y carto $\neg$ grafía de época medieval (II)” Al-Qanțara, 40.2: 455-475.

González, Ma. C., Cáceres, Y. y Ares, J. de. 2011. "En busca de Nūl Lamța. La aportación del estudio de la cerámica de Asrir (Guelmin, Marruecos)", en P. Cressier \& E. Frentress (eds.), La Céramique Maghré $\neg$ bine du haut Moyen Âge (VIIIe-Xe siècle): État des Recher $\neg$ ches, Problèmes et Perspectives. Roma: École française de Roma, 115-131.

Gordon, M. S., Robinson, Ch. F., Rowson, Everett K. y Fishbein, M. 2018. The Works of Ibn Wāọih al-Ya qūbī. An English Translation. Volume 1. The Geography. Kitāb alBuldān, Leiden - Boston, Brill.

Gsell, S. 1911. Atlas Archéologique de la Algerie. Édition spéciale des Cartes au 200.000e du Service Géographique de l'Armée avec un texte explicatif, Alger-Paris, Adolphe Jourdan-Fonemoing.

Hadj-Sadok, M., Ibn Khurradâdhbih, Ibn Faqîh al-Hamdhâni et Ibn Rustih. 1949. Description du Maghreb et de l'Europe au IIIe = IXe siècle. Extraits du «Kirâ al-Masâlik wa'l-Ma-malik», du «Kitâb al-Buldân» et du «Kitâb al-A lâq an-nafîsa». Texte arabe et tra-duction française, Alger, Editions Carbonell.

Hasan, M. 2003. al-Ŷugrāfiyā al-Tārījiyya li-Ifrīqiya min al-qarn al-awwal ilà al-qarn altāsi ' (H.) / al-qarn al-sābi' al-jāmis 'ašar (M.) Fușūl min Tārīj al-Mawāqi 'wa-lMasālik wa-l-Maŷalāt, Ṭarābulus, Dār al-Kitāb al-Ŷadīd al-Muttaḥida.

al-Idrīsī. 2002. Nuzhat al-mustāq fī ijtirāq al-āfāq. El Cairo: Maktabat al-Tạāāfa al-Dīniyya. 1999. Idrîsî. Le prèmier geographe de l'Occident. Trans. chevalier Jaubert. Eds. Henri Bresc \& Annliese Nef. Paris: GF Flammarion.

Kahlaoui, T. 2017. Creating the Mediterranean. Maps and the Islamic Imagination, Leiden-Bos-ton, Brill.

Kirschenbaum, M. 2012. "Digital Humanities As/Is a Tactical Term”, en M. K. Gold (ed.), Debates in The Digital Humanities, Minneaplois-London, 415-428.

Laoust, Émile. 1942. Contribution a une étude de la toponymie du Haut Atlas, Paris, Libraire Orientalist Paul Geuthner.

Leveau, Ph. 2018. "Climat, sociétés et environnement aux marges sahariennes du Maghreb: une aproche historiographique”, en S. Guédon, La frontière méridionale 
du Maghreb. Approches croisées (Antiquité-Moyen Âge), Bordeaux, Ausonius Éditions, 19-106.

Mahdi, M. 2007. Irguiten. Monographie d'une tribu du Haut-Atlas, Rabat, Institut Royal de la Culture Amazighe (IRCAM).

Manzano Rodríguez, M. A. 2016. "Las biografías del poder o la pretensión de un modelo: el caso del Magreb bajomedieval” eHumanista/IVITRA, 10: 364-374.

. 2017. "El Magreb desde Oriente: un acercamiento al Libro de los países de Ahmad al-Ya qūbī”, en F. Roldán y A. Contreras (eds.), Paisajes, espacios y objetos de devoción en el islam, Sevilla, Universidad de Sevilla, 141-160.

. 2019. "Breves notas sobre la toponimia magrebí recogida en la historiografía sobre Alfonso XI" en Diego Melo Carrasco y Miguel Ángel Manzano Rodríguez eds., AlAndalus y el Magreb. Miradas transatlánticas, Gijón, Trea, 121-130.

Marçais, G. 1941. "La Berbérie au IXe siècle”, Revue Africaine, 85: 41-61. 1991. "Ashīr", EI2, I, 699a.

Martínez Enamorado, V. 2013. “¿Árabes en el Valle del Genal? El topónimo Guaitará de Pujerra y los Banû Tamîm”, Takurunna: Anuario de Estudios sobre Ronda y La Serranía, 3: 380-386.

Martos Martín, J., Martínez Enamorado, Virgilio, y Navarro García, J. M. 2012. "Una propuesta de identificación arqueológica y etimo $\neg$ lógica para una alquería de la tierra de Estepona: Benamorave", Takurunna: Anuario de Estudios sobre Ronda y La Serranía, 2: 167-186.

Meouak, M. 2015. La langue berbère au Maghreb médiéval. Textes, contextes, analyses, Leiden, E. J. Brill.

Miquel, A. 1973-1988. La Géographie humaine du monde musulman jusqu’au milieu du 11 e siècle. Géographie et géographie humaine dans la littérature arabe des origines à 1050, Paris, Mouton, 4 vols.

Moussaoui, M. 2017. Révélations sur l'histoire des Berbères d'après une étude historique de la tribu des Oudjana des Aurès, s.l., Éditions Sabil.

Pellat, Ch. al-Muqaddasî. 1950. Description de l'Occident Musulman au IVe = Xe siècle. Texte arabe et traduction française, Alger, Editions Carbonell.

Pinto, K. C. 2016. Medieval Islamic maps. An exploration, Chicago-London, The University of Chicago Press,

Puig, N. 2003. Bédouins sédentarisés et société citadine à Tozeur (Sud-Ouest tunisien), Paris, IRMC-KARTHALA.

Ramou, H. (coord.) 2011. Les termes géographiques amazighes, Rabat, Institut Royal de la Culture Amazighe (IRCAM).

Rodríguez-Yunta, L. 2014. "Ciberinfraestructura para las humanidades digitales: una oportu-nidad de desarrollo tecnológico para la biblioteca académica”. El profesional de la información 23.5: 453-461.

Rojas Castro, A. 2013. "Las Humanidades Digitales: principios, valores y prácticas", Janus, 2: 74-99. Disponible en https://repositori.upf.edu/handle/10230/21517. 
Roldán, F. y R. Valencia. 1988. "El género al-masālik wa-l-mamālik: su realización en los textos de Al- 'Udrī y Al-Qazwīnī sobre el Occidente de Al-Andalus”, Philologia Hispa-lensis, 3: 7-26.

Spence, Paul. 2014. "Centros y fronteras: el panorama internacional de las humanidades digitales", Humanidades Digitales: desafíos, logros y perspectivas de futuro. Janus, Anexo 1: 37-61.

Terés, E. 1986. Materiales para el estudio de la toponimia hispanoárabe. Nómina Fluvial, Madrid, CSIC.

Tibbets, G. R. 1992. “The Balkhī School of Geographers” en J. B. Harley y David Woodward eds., The History of Cartography. Cartography in the Traditional Islamic and South Asian Societies, Chicago - London, The University of Chicago Press, II/1: 108-136.

Tixier du Mesnil, E. 2014. Géographes d'al-Andalus. De l'inventaire d'un territoire à la cons-truction d'une mémoire, Paris, Publications de la Sorbonne.

Van Stäevel, J.-P. y Fili, A. 2006. "Wa-wașalnā 'alà barakāt Allāh ilà İgìlìz. À propos de la localization d'İgilīiz-des-Harg̉a, le hịṣn du Mahdī Ibn Tūmart”, Al-Qanțara, 27/1: 155-197.

Vignet-Zunz, J. J. 2017. Sociétés de montagnes méditarréennes. Ouarsenis (Algérie), Jabal Al-Akhḍar (Libye), Rif (Maroc), Paris, L'Harmattan.

al-Ya qūbī, Kitāb al-buldān, ed. M. J. 1891. De Goeje. Leiden: E. J. Brill.

Yāqūt al-Ḥamawī, Mu' yam al-buldān, ed. Farīd. 2012. 'Abd al'Azīz al-Jundī, Beirut: Dār al-Kutub al-'Ilmiyya,

\section{Referencias a páginas WEB}

Algolia Search Online, https://www.algolia.com.

Analysis of the Artistic Exchanges in the Medieval Mediterranean between 12th and 15th Centuries through the Geographical Information Systems (GIS): A Critical Review of "Centre" and "Peripheries", http://fabricadesites.fcsh.unl.pt/artmedgis/Arabismo. com, disponible a través de http://web.archive.org.

AVBRE: Arabic Varieties Bibliographic References - Referencias bibliográficas de variedades árabes, https://avbre.usal.es.

Bibliotheca Geographorum Arabicorum, ed. M.J. de Goeje, Leiden, Brill, 1870-1894, https://brill.com/view/serial/BGA.

Bibliothèque Numérique Marocaine; http://bnm.bnrm.ma:86.

CORVAM: Corpus oral de variedades magrebíes (resultado a su vez de dos proyectos: Fronteras lingüísticas y factores sociales: perspectivas sincrónicas y diacrónicas de la región del Magreb y Patrimonio sociolingüístico en el Magreb: tradición oral y capital cultural, http://corvam.unizar.es.

CRONOISLAM, https://cronoislam-f6a2b.web.app.

Diccionario de toponimia magrebí en la red, https://dictomagred.usal.es. 
Encyclopédie Berbère, https://encyclopedieberbere.revues.org/.

GALLICA, https://gallica.bnf.fr.

Geografía Cultural del Mágreb Islámico y Dinámicas Humanas en el Norte de África (MAGNA), https://proyectomagna.org.

Keyman Desktop, https://keyman.com/desktop. Para este programa se ha construido el módulo Ibn Jaldún, desarrollado por M. A. Manzano y disponible en https://bit. ly/2H0EnyZ.

KOHEPOCU: Knowledege, Heresy and Political Culture in the Islamic West (eight-fifteenth centuries), http://kohepocu.cchs.csic.es.

Al-Maktaba al-Shamela, http://shamela.ws/.

Prosopografía de los ulemas de al-Andalus, https://www.eea.csic.es/eea-proyectos-investigacion-terminados-recientemente/prosopografia-de-los-ulemas-de-al-andalusffi2010-20428/.

Redes de sabios andalusíes. Estructuras de transmisión del saber y relaciones, https://rtsa. eea.csic.es.

Sil International, https://www.sil.org/resources.

The Encyclopaedia of Islam, THREE, ed. Brill, https://referenceworks.brillonline.com/ browse/encyclopaedia-of-islam-3.Al-Warrāq, http://www.alwaraq.net/Core/index.jsp 